\title{
Optical partitioning for multicarrier generation in subcarrier multiplexed networks
}

\section{Particionado óptico para la generación multiportadora en redes multiplexadas en subportadora}

\author{
DOI: http://doi.org/10.17981/ingecuc.16.1.2020.013 \\ Artículo de Investigación Científica. Fecha de Recepción: 03/06/2019. Fecha de Aceptación: 23/01/2020 \\ Fabián Ranulfo Cuesta Quintero \\ Universidad Francisco de Paula Santander. Ocaña (Colombia) \\ fcuestaq@ufpso.edu.co \\ Gustavo Adolfo Puerto Leguizamón (1) \\ Universidad Distrital Francisco José de Caldas. Bogotá (Colombia) \\ gapuerto@udistrital.edu.co \\ Carlos Arturo Suárez Fajardo \\ Universidad Distrital Francisco José de Caldas. Bogotá (Colombia) \\ csuarezf@udistrital.edu.co
}

Para citar este artículo:

F. Cuesta Quintero, G. Puerto Leguizamón y C. Suárez Fajardo, "Optical partitioning for multicarrier generation in subcarrier multiplexed networks", INGE CUC, vol. 16, no. 1, pp. 180-186, 2020. DOI: http://doi.org/10.17981/ingecuc.16.1.2020.013

\begin{abstract}
Objective- To evaluate the multicarrier generation technique based on spectral segmentation for the transport of optical subcarrier multiplexing signals.

Methodology- The proposal is evaluated through experimental validation and modeling based on simulation of the generation of optical carriers using a broadband source in combination with an optical filter configured with different pass bands and transmission at different distances.

Results- The experimental evaluation measured the Error Vector Magnitude (EVM) for $1 \mathrm{~nm}, 3 \mathrm{~nm}, 6 \mathrm{~nm}$ and $8 \mathrm{~nm}$ optical slices that transport QPSK and 16QAM modulation formats at $1 \mathrm{GHz}$ and $3 \mathrm{GHz}$ subcarriers over a fiber link of $10 \mathrm{~km}$. For the case of $1 \mathrm{~nm}$ pass band and QPSK modulation, an EVM of $29.6458 \%$ was found while an EVM of $40.4685 \%$ for the service transported in 16QAM was measured. The simulation model showed that a bit error rate of $1 \times 10^{-12}$ is achieved for spectral partition sizes of $100 \mathrm{MHz}$ on $5 \mathrm{GH}, 30 \mathrm{GHz}$ and $60 \mathrm{GHz}$ subcarriers.

Conclusions- The experimental results showed that the measured EVM did not show significant difference regarding the subcarrier frequency for a QPSK service. However, the 16QAM modulation is recommended only when the subcarrier frequency is $1 \mathrm{GHz}$ or below for a correct equalization of the received signal. Simulation modeling evaluated the approach at higher subcarrier frequencies and longer distances, results found show that a $60 \mathrm{GHz}$ subcarrier over a fiber link of $40 \mathrm{~km}$ is feasible for a slice size of $100 \mathrm{MHz}$.
\end{abstract}

Keywords- Spectral partitioning, subcarrier multiplexing, wavelength division multiplexing, Radio over Fiber, Optical access networks, Broadband optical sources

\section{Resumen}

Objetivo- Evaluar la técnica de generación multiportadora basada en segmentado espectral para el transporte de señales de señales multiplexadas en subportadora óptica.

Metodología- La propuesta se evalúa mediante validación experimental y modelamiento basado en simulación de la generación de portadoras ópticas utilizando una fuente de banda ancha en combinación con un filtro óptico configurado con diferentes bandas de paso y transmisión a diferentes distancias.

Resultados- La evaluación experimental midió la magnitud del vector de error para particiones espectrales de $1 \mathrm{~nm}, 3 \mathrm{~nm}, 6 \mathrm{~nm}$ y $8 \mathrm{~nm}$ que transportan formatos de modulación QPSK y 16QAM en subportadoras de $1 \mathrm{GHz}$ y $3 \mathrm{GHz}$ a través de un enlace de fibra de $10 \mathrm{~km}$. Para una banda de paso de $1 \mathrm{~nm}$ y modulación QPSK, se encontró un EVM de $29.6458 \%$ mientras que un EVM de $40.4685 \%$ fue medido para el servicio transportado en 16QAM. El modelo de simulación mostró que una tasa de error de bit de $1 \times 10^{-12}$ se logra para tamaños de particiones espectrales de $100 \mathrm{MHz}$ en subportadoras de $5 \mathrm{GH}, 30 \mathrm{GHz}$ y $60 \mathrm{GHz}$.

Conclusiones- Los resultados experimentales mostraron que el EVM medido no mostró una diferencia significativa con respecto a la frecuencia de la subportadora para un servicio QPSK. Sin embargo, la modulación 16QAM se recomienda solo cuando la frecuencia de la subportadora es $1 \mathrm{GHz}$ o inferior para una ecualización correcta de la señal recibida. El modelo de simulación evaluó la propuesta en frecuencias subportadoras más altas y distancias más largas. Los resultados encontrados muestran que una subportadora de $60 \mathrm{GHz}$ sobre un enlace de fibra de $40 \mathrm{~km}$ es posible cuando el tamaño de la partición óptica es de $100 \mathrm{MHz}$. Palabras clave- Particionado espectral; Multiplexación de subportadora; Multiplexación por división de longitud de onda; Radio sobre fibra; Redes de acceso óptico; Fuentes de banda ancha 


\section{INTRODUCTION}

The advent of future $5 \mathrm{G}$ networks is putting into evidence the need for a convergence of wireless and optical networks in order to ease the network evolution towards the transport of high-capacity mobile devices and data-intensive applications [1]. This convergent scenario envisages that both mobile and fixed services will be transported and distributed using the same physical platform. In this context, the use of Radio over Fiber (RoF) techniques based on Subcarrier Multiplexing (SCM) provides a new level of multiplexing over each optical channel that facilitates the transport of mobile services directly on its original radio frequency signal. This fact enables a WDM-SCM hybrid-multiplexing system, in which there is an independent information channel for each one of the subcarriers that make up each one of the WDM optical channels. The advantage of this combined multiplexing scheme is that it enables each carrier to be routed to a specific radio front-end based on the wavelength value. Thus, it is envisaged a wide range of new strategies to provide transport services for small and dense cells to cost-effectively support the continuous cell densification [2]. One of such strategies deals with the reduction of the optoelectronic devices used in the transmitting side of an optical network. In this context, multicarrier generation techniques have attracted attention in order to provide solutions for the growing deployment of fixed and mobile broadband networks.

Related work has dealt with multicarrier generation based on optical frequency comb shaping techniques. Recently, an approach using three modulators in cascade and a laser source that is connected with one amplitude modulator and two Mach-Zehnder Modulators (MZMs) in cascade is described [3]. In this approach, a multi-carrier optical generator on the side of the OLT that supports numerous users, reduce the costs of the Optical Line Terminal (OLT) of the conventional Wavelength Division Multiplexed Passive Optical Network system (WDM-PON). Also, an approach that generates optical carriers provided by an optical frequency comb with externally injected gain switching is presented [4]. In such proposal each optical channel transmitted an orthogonal subcarrier multiplexing (SCM) signal of $21.6 \mathrm{~Gb} / \mathrm{s}$ at 30 $\mathrm{GHz}$ which was modulated and demodulated in the electrical domain. Another channelization scheme for a wideband radio-frequency (RF) signal based on an Optical Frequency Comb (OFC) is presented where a comb filter and an optical demux is proposed and demonstrated [6]. In this approach, the input broadband Radio Frequency (RF) signal is multicast by a $39 \mathrm{GHz}$-spaced OFC and sliced by a
Fabry-Pérot filter (FPF). Also, an approach for fast wireless information transmission using spectrumsliced super-continuum along the $\mathrm{THz}$ frequency range is described [7] and a demonstration of a spectrum-sliced wavelength division multiplexed passive optical network with the channel spacing of $25 \mathrm{GHz}$ is presented [8].

In this work, we propose an optical architecture for the multicarrier generation in subcarrier multiplexing networks. The approach is assessed in a testbed and subsequently a simulation model allows evaluating its performance at different subcarrier frequencies, distances and pass band values. The underlying contribution of this work lies in the simplified way of generating multiple optical channels based on the spectral partitioning of a broadband optical source through a wideband optical filter. Unlike the related proposals described previously, this approach enables the generation and transport of optical carriers to feed the SCM network using wider pass bands than those used and demonstrated in the state of the art. We believe that this unique feature leads to a cost-effective multicarrier generation system for subcarrier multiplexed transport in network segments covering the required distances of future small cells and high density cells scenarios expected in future $5 \mathrm{G}$ networks.

This paper is organized as follows, section 2 describes the proposed architecture and the implementation details of the approach, section 3 presents and discusses the experimental and modeling results and section 4 summarizes the paper.

\section{Materials AND Methods}

Fig. 1 shows the layout of a subcarrier-multiplexed network in which our approach can be included in order to provide the optical carriers. Overall, the system consists of a broadband source that feeds the demux filter responsible for partitioning the optical spectrum emitted by the broadband source. After carrier generation, a multiplexed comb is sent to the access segment through the optical circulator (a), which directs the unmodulated carrier to the optical modulator in each one of the base stations of the access network to conform the uplink signal in this segment. Once the RoF signal has been obtained, the optical circulator (b) enables the uplink and directs the signal towards the metro network. Subsequently, a 1x2 optical splitter is responsible for distributing the RoF signal equally to the Optical Add-Drop Multiplexer (OADM). The OADM consists of optical switches and an arrangement of Arrayed Waveguide Gratings (AWG), which are in charge of defining the inputs and outputs of the system. 


\section{A. Implementation details}

The experimental setup shown in Fig. 2 includes a Broadband Source (BBS) that generates an optical spectrum from 1000nm to 2000nm. This broadband signal enters the demux filter centered at $1550 \mathrm{~nm}$. The pass bands of the filter sliced optical bandwidths of $1 \mathrm{~nm}, 3 \mathrm{~nm}, 6 \mathrm{~nm}$ and $8 \mathrm{~nm}$ that were used as optical sources to the Mach-Zehnder Modulator (MZM). The approach is evaluated in terms of the performance provided by using broadband optical slices and its impact on the available bandwidth modulation capability. Also, by measuring the Error Vector Magnitude (EVM), the quality of the transported signals was also assessed. For the experimental validation a Vector Network Analyzer (VNA) feeds the system with frequencies from $5 \mathrm{MHz}$ up to $5 \mathrm{GHz}$. Then, the optical modulated signal is amplified $15 \mathrm{~dB}$ before the transmission through the optical fiber. After the propagation on fiber of the
SCM signals, an optical attenuator (ATT) emulates additional optical losses of the approach and a Photo Detector (PD) enables the analysis and evaluation of the transported signals.

The layout of the implementation for the experimental demonstration is shown in Fig. 2 and a simulation model was carried out in order to evaluate the performance of the approach under different parameter configurations in Optisystem, the results are described in section III.A. The experimental demonstration was performed with the arbitrary waveform generator M8190A where the I/Q signals where generated and subsequently up-converted in the E8663D PSG RF analog signal generator. The down-conversion was performed in the N9020A (MXA) Signal Analyzer. In this scenario, Dual-Polarization Quadrature Phase Shift Keying (QPSK) and the 16QAM (Quadrature Amplitude Modulation) transporting 10 Mbauds onto $3 \mathrm{GHz}$ were used.

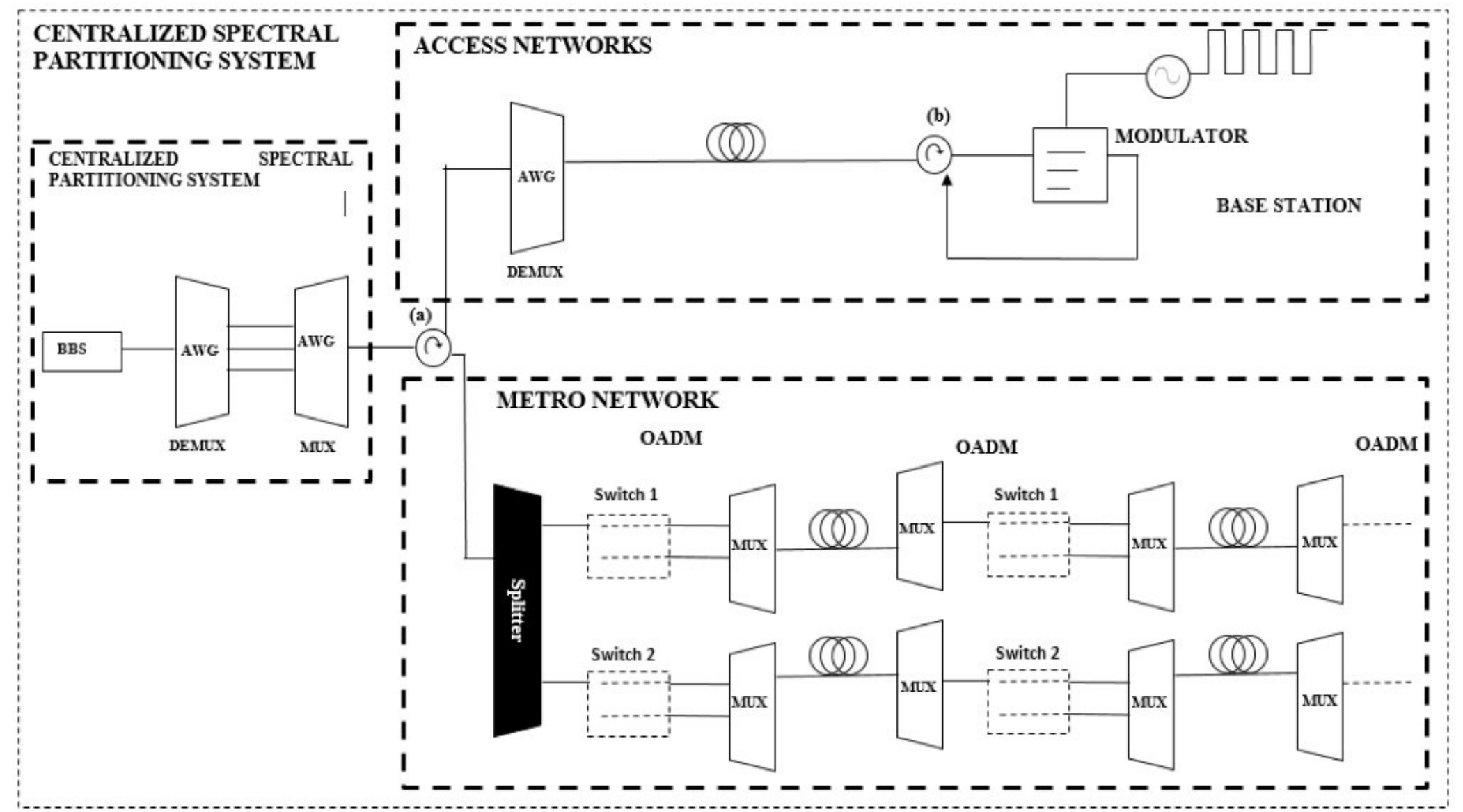

Fig. 1. Layout of the centralized spectral slicing for access-metro networks. Source: Authors.

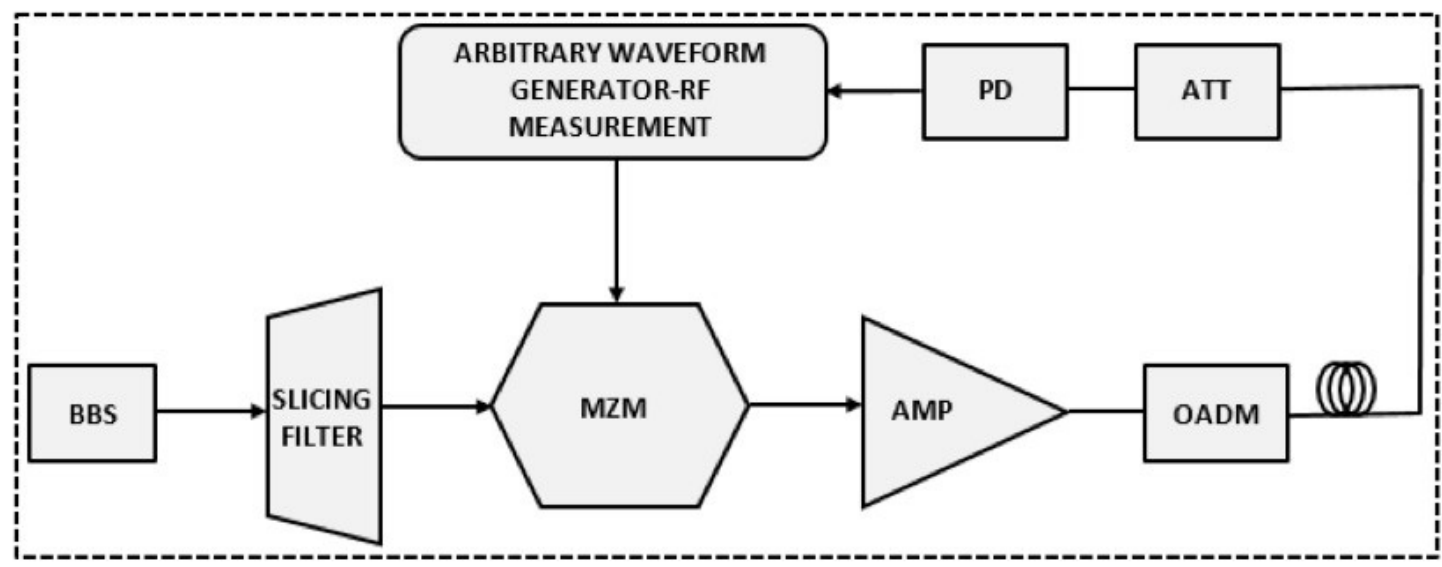

Fig. 2. Layout of the experimental demonstration for the proposed system. Source: Authors. 


\section{RESULTS}

The results of the power characterization for the defined pass bands given by the slicing filter at different fiber lengths are shown in Fig. 3. As it can be seen, the thinner the slice size the lower the optical power and the wider the pass band the higher the power available per carrier. It means that the slice size impacts directly on the optical power available per generated carrier. For that reason an EDFA amplifier was used to increase the power level at the transmitter output in the experimental characterization.

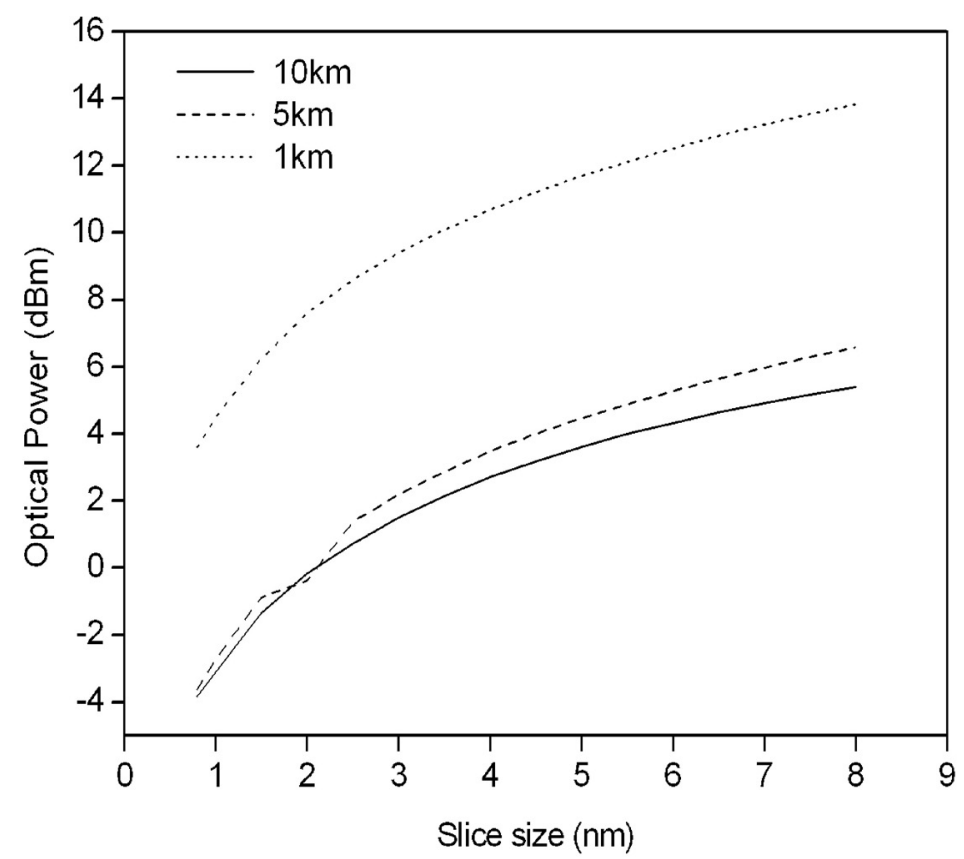

Fig. 3. Power as a function of the slice size. Source: Authors.

Fig. 4 shows the behavior of different RF frequencies against different slice sizes at different lengths. As seen, shorter distances imply wider modulation bands e.g. in the case of a pass band of $1 \mathrm{~nm}$, a modulation band of $2.7 \mathrm{GHz}$ was found for $1 \mathrm{~km}$ fiber length. In this scenario, it was generally observed that the modulation band capacity decreases as the pass band and transmission distance increases. It is also worth mentioning that no dispersion compensation process was performed, which implies that the results for the 5 and $10 \mathrm{~km}$ case can be improved in terms of the available modulation bandwidth of the generated carrier. In the same way, the carrier suppression effect was not observed in the experimental assessment. Fig. 5 depicts the constellations for $3 \mathrm{GHz}$ SCM/QPSK and $3 \mathrm{GHz} \mathrm{SCM} / 16 \mathrm{QAM}$ on $1 \mathrm{~nm}, 3 \mathrm{~nm}, 6 \mathrm{~nm}$ and $8 \mathrm{~nm}$ slice sizes respectively. It is observed that for a slice size of $1 \mathrm{~nm}$ the constellation is clean in both modulations, whereas for a pass band of $3 \mathrm{~nm}$ and $6 \mathrm{~nm}$ respectively the constellations turn noisier particularly in the 16QAM modulation.

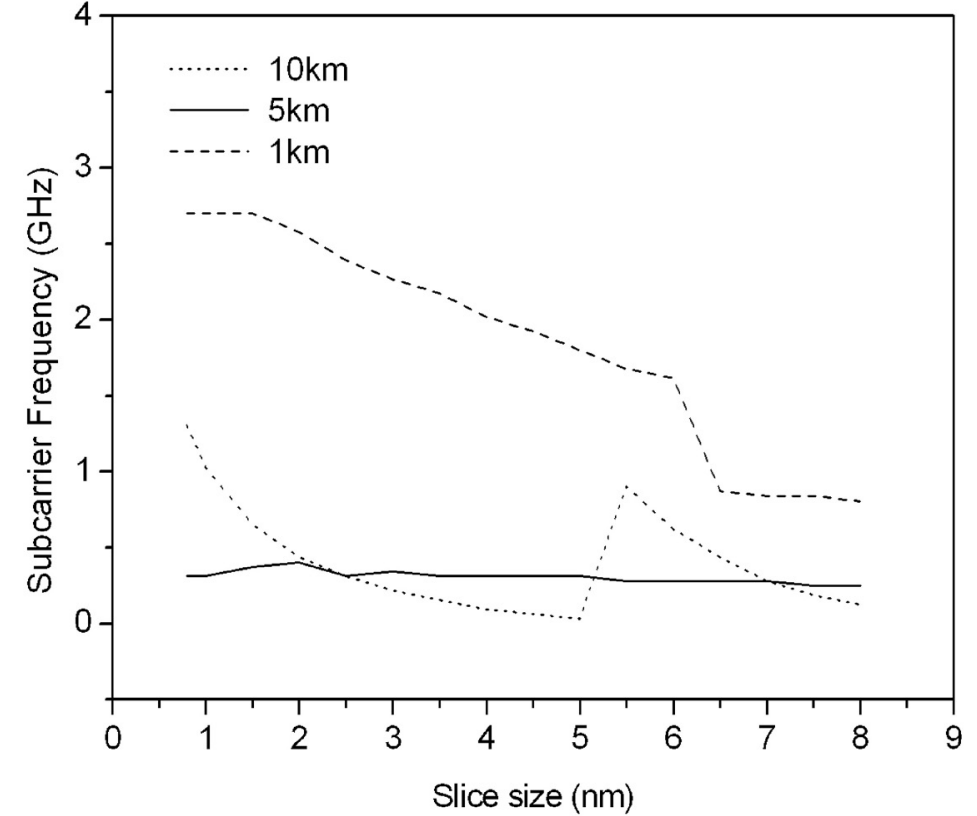

Fig. 4. Bandwidth modulation as a function of the slice size. Source: Authors.

(a)

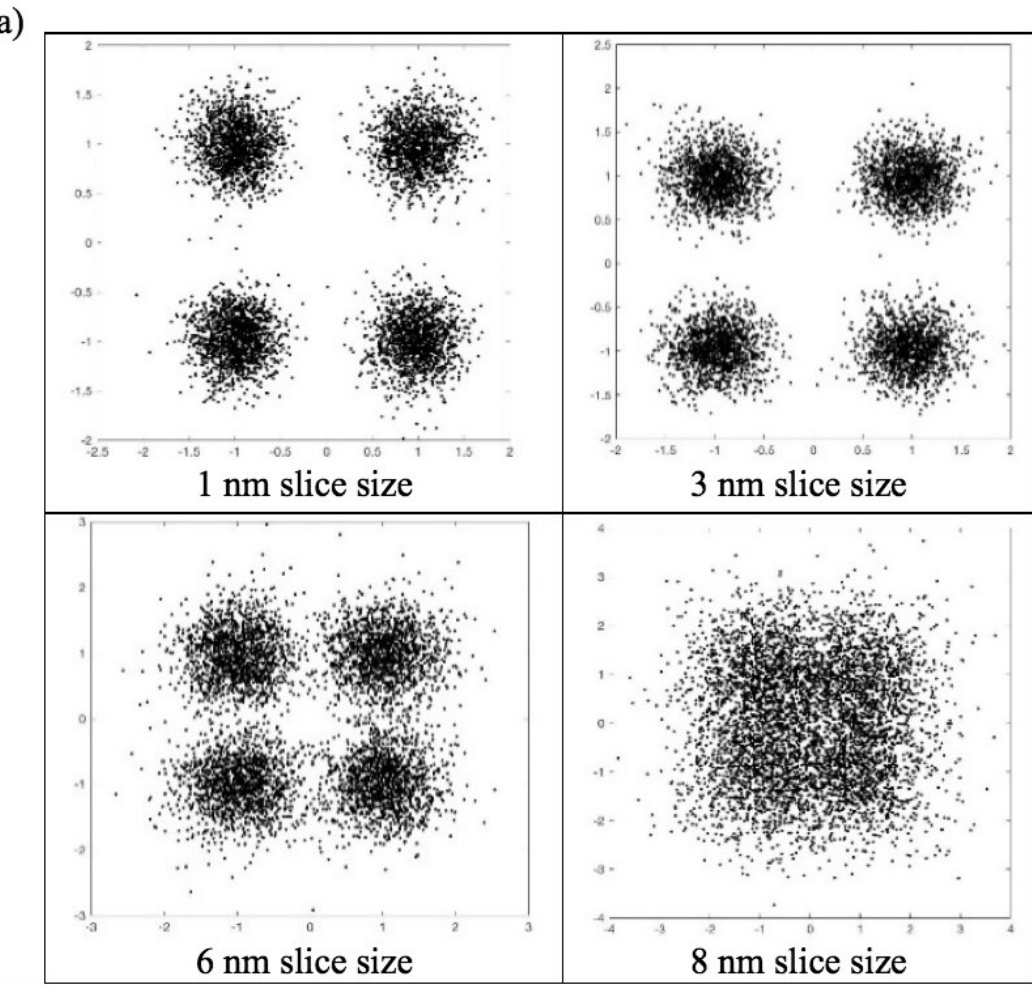

(b)

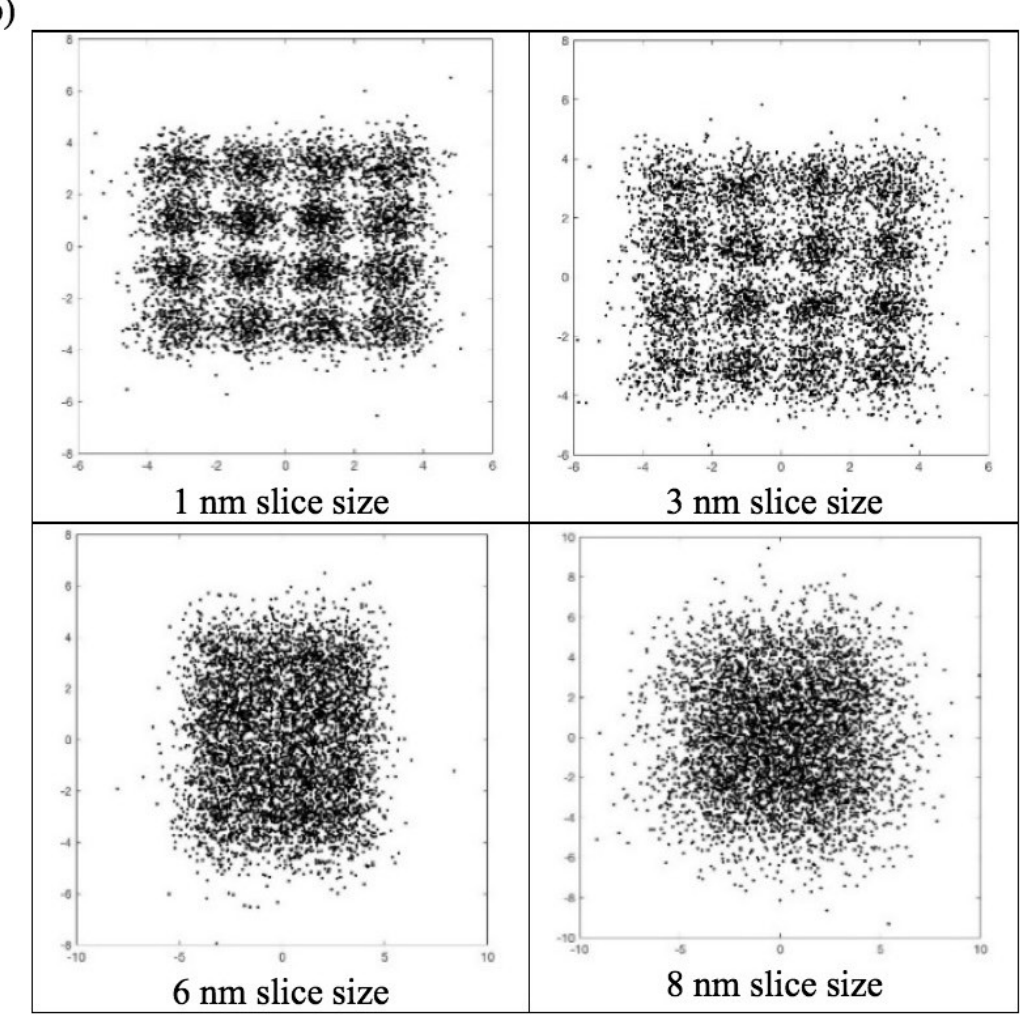

Fig. 5. Experimental results: (a) Constellation for $3 \mathrm{GHz}$ SCM/QPSK. (b) $3 \mathrm{GHz}$ SCM/16QAM. Measurements performed after a $10 \mathrm{~km}$ optical link. Source: Authors. 
For a pass band of $8 \mathrm{~nm}$ the signal is not detectable at all in any of the evaluated modulations. These facts demonstrate that the quality of the signal is reduced, as the slice sizes are broader. In this context, broader slice sizes affect the higher multilevel modulation significantly due to the accumulated chromatic dispersion, which prevent to get a tolerable quality of signal. Such behavior can be observed in Fig. 6 where the EVM per subcarrier and EVM per symbol were measured for the QPSK service transported onto a subcarrier of $3 \mathrm{GHz}$. Fig. 6(a) shows the results for a $1 \mathrm{~nm}$ optical slice size, Fig. 6(b) depicts the results for an slice size of $3 \mathrm{~nm}$ and Fig. 6(c) shows the performance for a slice size of $6 \mathrm{~nm}$.

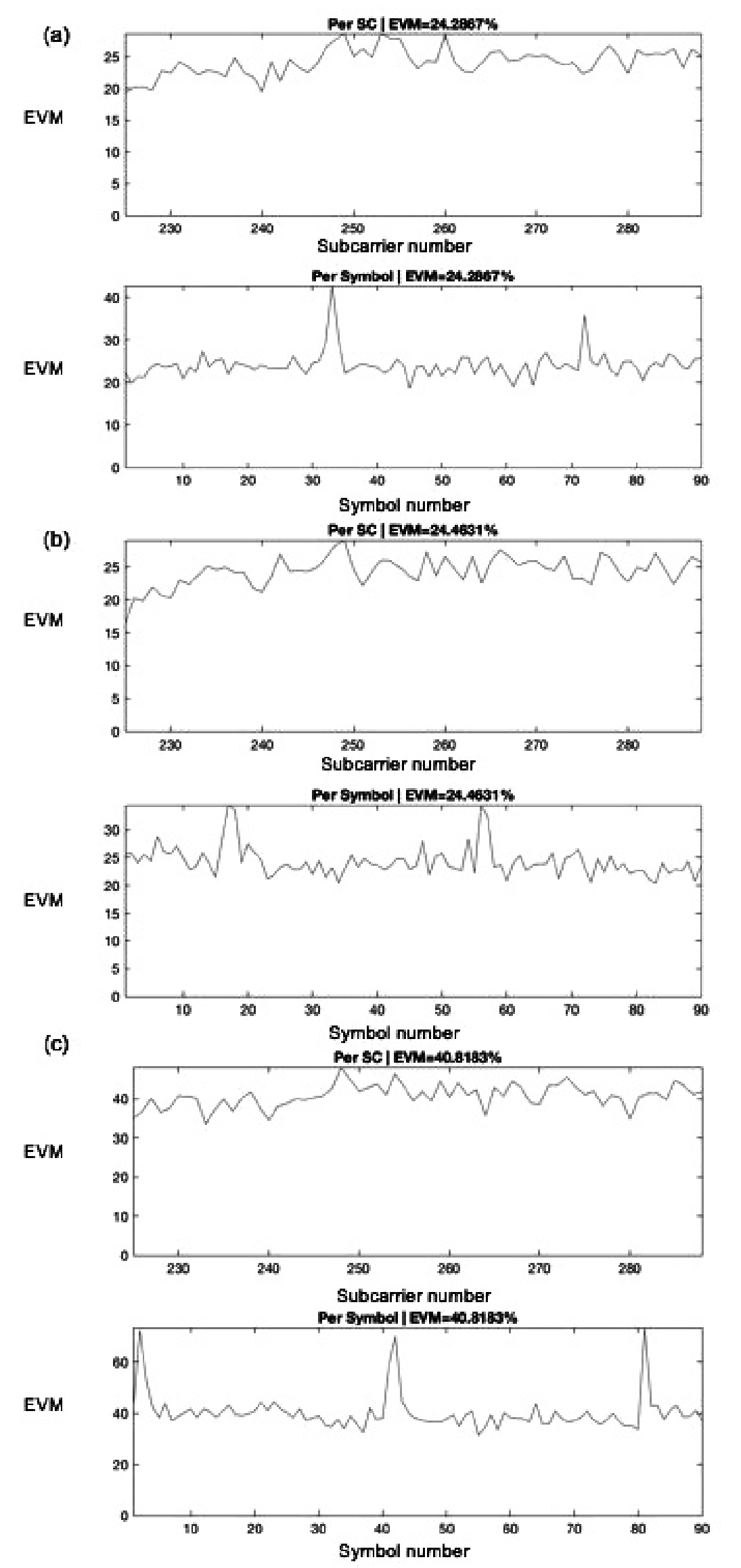

Fig. 6. Experimental results: EVM per subcarrier and EVM per symbol for the QPSK service at $3 \mathrm{GHz}$ transmitted at different optical bandwidths, (a) $1 \mathrm{~nm}$. (b) $3 \mathrm{~nm}$. (c) $6 \mathrm{~nm}$. Source: Authors.
These results confirm that the EVM improves, as the slice size is narrower due to the relative lower impact of the chromatic dispersion as seen in the constellations shown in Fig. 5. Notice that for $1 \mathrm{~nm}$ and $3 \mathrm{~nm}$ slice sizes the EVM is around $20 \%$ whereas for $6 \mathrm{~nm}$ the EVM scales up to $40 \%$ in the QPSK modulation. Fig. 7 summarizes the behavior of the QPSK and 16 QAM modulation formats at $1 \mathrm{GHz}$ and $3 \mathrm{GHz}$ subcarriers transported on the defined pass bands and a constant fiber length of $10 \mathrm{~km}$. For the case of $1 \mathrm{~nm}$ pass band transporting $1 \mathrm{GHz}$ SCM/QPSK, the EVM was $29.6 \%$ while an EVM of $42.3 \%$ was measured for $1 \mathrm{GHz}$ SCM/16QAM. Note that the degradation depends on the available pass band and on the modulation used as observed in the constellations shown in Fig. 5. The results obtained with slice sizes broader than $6 \mathrm{~nm}$ indicate that unless additional processing to mitigate the chromatic dispersion is included, this pass band is not suitable to transport a subcarrier-multiplexed service with a good level of quality assurance.

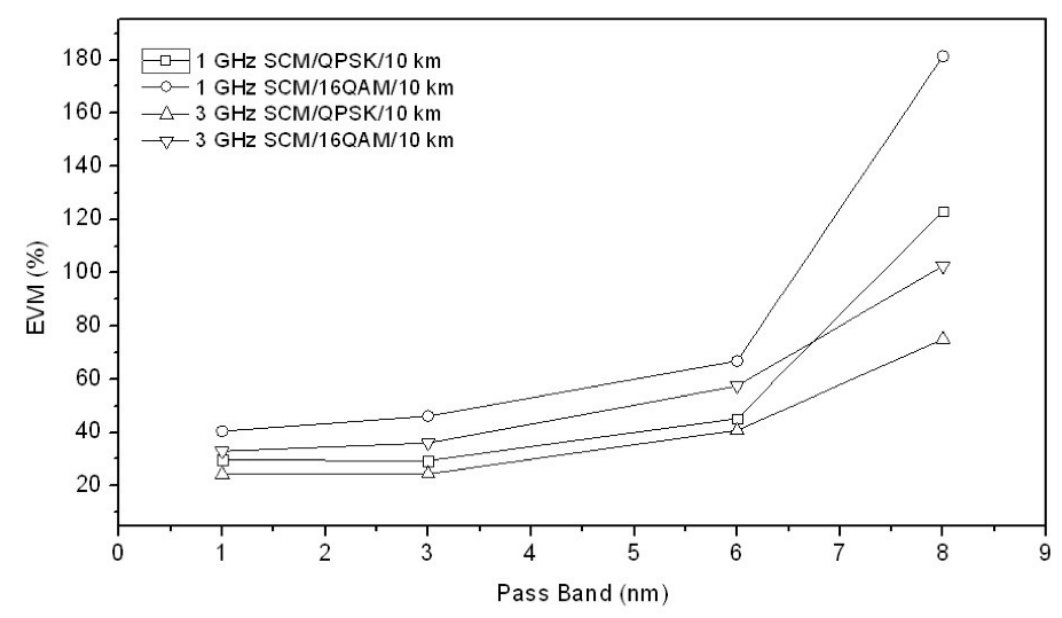

Fig. 7. Experimental results: EVM measurement for $1 \mathrm{GHz}$ SCM/QPSK, 1GHz SCM/16QAM, 3GHz SCM/QPSK and 3 $\mathrm{GHz}$ SCM/16QAM. Source: Authors.

\section{A. Simulation results}

The simulation based modeling of the general scheme was performed in Optisystem in order to assess the approach based on the subcarrier frequency, the distance and the pass band parameters. Unlike the experimental assessment, the carrier suppression effect indeed appeared in the simulations due to the longer distances evaluated. It must be also pointed out that the modeling evaluation includes narrower slice sizes and different services as compared to those used in the experimental assessment described previously. This fact allows evaluating the performance using different types of filters and pattern traffic transported in the system. In this context, the modeled slice sizes were $100 \mathrm{MHz}$ and $200 \mathrm{MHz}$ and the bit rate was $1 \mathrm{~Gb} / \mathrm{s}$ Non-Return to Zero (NRZ) encoded that was assessed through the $\mathrm{Q}$ factor measurement. As far the subcarrier is concerned, $5 \mathrm{GHz}, 30 \mathrm{GHz}$ and $60 \mathrm{GHz}$ were used. The transmission distance was swept from $5 \mathrm{~km}$ 
to $50 \mathrm{~km}$ in steps of $5 \mathrm{~km}$, Fig. 8 and Fig. 9 show the corresponding results for an optical pass band of $100 \mathrm{MHz}$ and $200 \mathrm{MHz}$ respectively. The results obtained in the conducted simulations for a $100 \mathrm{MHz}$ optical pass band used, show that by considering a limit $\mathrm{Q}$ factor of 7 (dotted line in Fig. 8), which roughly corresponds to a bit error rate of $1 \times 10^{-12}$, the subcarriers at $5 \mathrm{GHz}$ and $30 \mathrm{GHz}$ reach a propagation distance of up to $50 \mathrm{~km}$ while the $60 \mathrm{GHz}$ subcarrier reaches the quality of signal limit at a maximum propagation of $40 \mathrm{~km}$.

Notice in Fig. 9 the strong degradation of the $Q$ factor when a slice size of $200 \mathrm{MHz}$ was used as compared to the result found for a slice size of $100 \mathrm{MHz}$. This fact is due to the pulse broadening effect caused by a broader optical carrier. In this case only the $30 \mathrm{GHz}$ subcarrier is able to satisfy the quality of signal limit only at certain transmission distances. This interesting behavior comes from two reasons; the first one is due to the strongly number of harmonic distortion products that are absorbed by the photodetector with a $5 \mathrm{GHz}$ subcarrier, whereas the degradation of the $60 \mathrm{GHz}$ comes from the bandwidth limitation of the optical modulator used in the simulations. The second reason for such behavior is due to the higher differential group delay generated by the $200 \mathrm{MHz}$ optical pass band, which in turn causes the generation of the carrier suppression effect that makes the signal at $30 \mathrm{GHz}$ unable to be recovered from $9 \mathrm{~km}$ to $21 \mathrm{~km}$ and from $28 \mathrm{~km}$ to $37 \mathrm{~km}$.

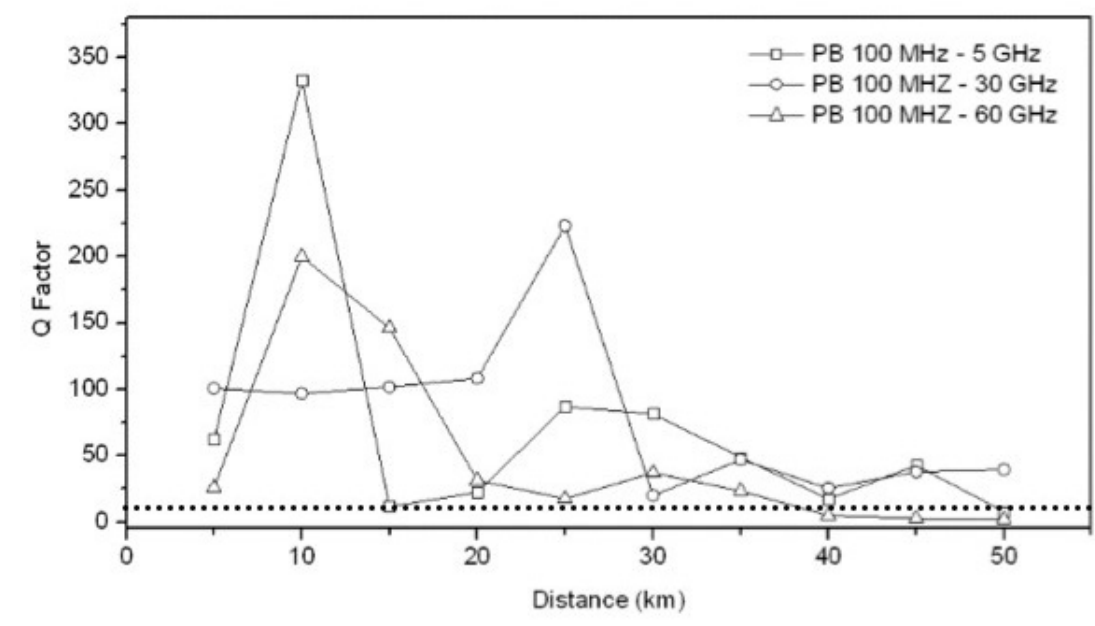

Fig. 8. Modeling results: Q factor vs. distance for $100 \mathrm{MHz}$ pass band. Source: Authors.

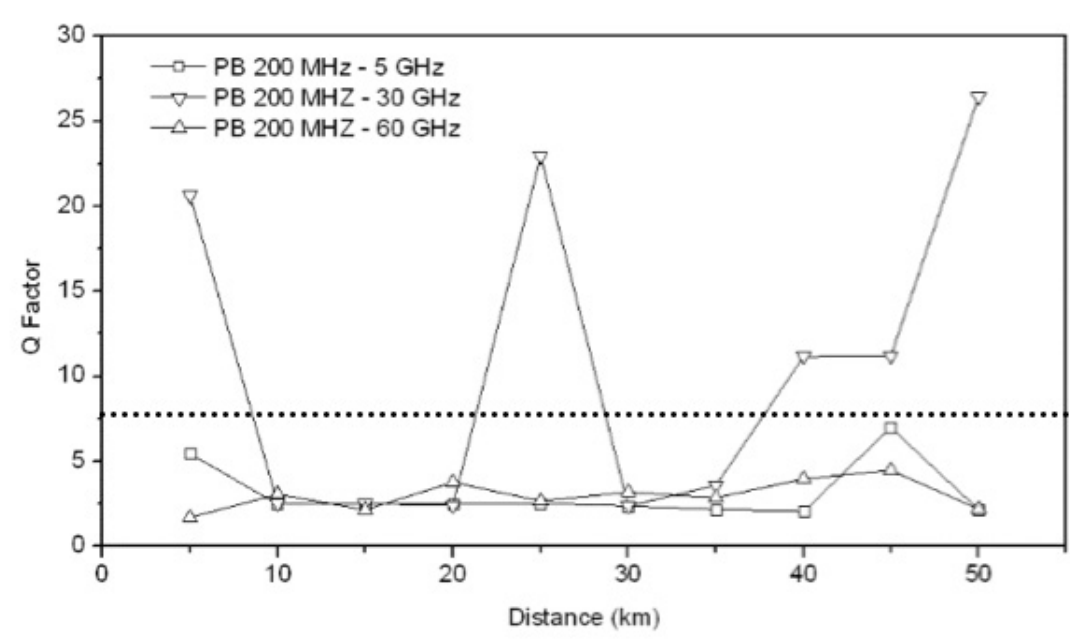

Fig. 9. Modeling results: $Q$ factor vs. distance for $200 \mathrm{MHz}$ pass band. Source: Authors.

\section{Conclusions}

This paper evaluates the use of a broadband light source and a wideband optical filter in order to generate optical carriers for the transmission of subcarrier-multiplexed signals in next generation access networks. The approach was evaluated through experimental demonstration and simulation modeling. Based on the conducted experimental measurements, the power response of the system improves depending on the optical pass band defined in the slicing filter at subcarrier frequencies below $1 \mathrm{GHz}$. It was observed that the narrower the pass bands in the filter, the better the response in the receiver due to the chromatic dispersion penalties imposed by the standard monomodo optical fiber. However, it should be taken into account that a narrow optical pass band leads to a lower average optical power. Thus, the signal quality depends on the compromise between the optical power and the dispersion for a given optical pass band. The experimental results demonstrated that the 16QAM modulation is recommended only when the subcarrier frequency is $1 \mathrm{GHz}$ or below, the optical pass band is lower than $3 \mathrm{~nm}$ and the maximum length link is $10 \mathrm{~km}$ in order to enable a correct equalization of the received signal. The measured EVM did not show significant difference regarding the subcarrier frequency for a QPSK service; therefore, a QPSK format modulated onto an optical subcarrier is feasible to be transported within broadband optical carriers up to $6 \mathrm{~nm}$ wide over a fiber link of $10 \mathrm{~km}$. The modeling results allowed predicting the performance of the proposed approach at higher subcarrier frequencies and longer optical links using narrow slice sizes. Thus, a $60 \mathrm{GHz}$ subcarrier-multiplexed system over $40 \mathrm{~km}$ and a slice size of $100 \mathrm{MHz}$ is suitable to satisfy $1 \times 10^{-12}$-bit error rate. $5 \mathrm{GHz}$ and $30 \mathrm{GHz}$ subcarrier frequencies reach up to $50 \mathrm{~km}$ due to the reduced contribution of the chromatic dispersion. For a slice size of $200 \mathrm{MHz}$ the combination of the accumulated differential group delay, distance and subcarrier frequency causes the carrier suppression effect which prevents a proper operation of the system. This effect could not be observed in the experimental demonstration due to the shorter distance evaluated a lower value of the subcarrier frequency used. Overall, the results found in the experimental measurements and the simulation modeling demonstrate the feasibility of the proposed approach to generate a multicarrier optical signal for subcarrier multiplexed networks that provide the transport to future mobile systems. 


\section{REFERENCES}

[1] D. Villafani, R. P. Almeida, P. J. Urban, J. C. W. A. Costa, J. P. Von Der Weid \& J. Chen, "SCM/WDM-PON with in-service baseband embedded OTDR monitoring," Opt. Commun., vol. 356, pp. 250-255, Dec. 2015. https://doi. org/10.1016/j.optcom.2015.08.003

[2] Cisco Visual Networking Index: Forecast and Trends, Ed. 2017-2022. Cisco, San José, CA, 2017. [Online]. Available: https://www.cisco.com/c/en/us/solutions/collateral/service-provider/visual-networking-index-vni/whitepaper-c11-741490.html

[3] R. P. Almeida, R. S. Oliveira, N. S. Moritsuka, C. R. L. Francês, A. Teixeira \& J. C. W. A. Costa, "Digital radio over fiber transmission based on SCM and WDM system for C-RAN architecture," in 2014 International Telecommunications Symposium, ITS, São Paulo, BR, pp. 1-5. https://doi.org/10.1109/ITS.2014.6947987

[4] R. Ullah, L. Bo, S. Ullah, M. Yaya, F. Tian, M. K. Khan \& X. Xiangjun "Flattened optical multicarrier generation technique for optical line terminal side in next generation WDM-PON supporting high data rate transmission," IEEE Access, vol. 6, no. c, pp. 6183-6193, Jan. 2018. https://doi.org/10.1109/ACCESS.2018.2789863

[5] F. A. Gutiérrez, E. P. Martin, P. Perry, A. D. Ellis, P. M. Anandarajah \& L. P. Barry, "WDM Orthogonal Subcarrier Multiplexing," J. Light. Technol., vol. 34, no. 8, pp. 1815-1823, Apr. 2016. https://doi.org/10.1109/ JLT.2015.2508418

[6] X. Xie, Y. Dai, Y. Ji, K. Xu, Y. Li, J. Wu \& J. Lin, "Broadband Photonic Radio-Frequency Channelization Based on a 39-GHz Optical Frequency Comb," IEEE. Photonic. Tech. L., vol. 24, no. 8, pp. 661-663, Apr. 2012. https:/l doi.org/10.1109/LPT.2012.2185787

[7] Y. V. Grachev, X. Liu, S. E. Putilin, A. N. Tsypkin, V. G. Bespalov, S. A. Kozlov \& X-Ch. Zhang, "Wireless Data Transmission Method Using Pulsed THz Sliced Spectral Supercontinuum," IEEE. Photonic. Tech. L., vol. 30, no. 1, no. 1, pp. 103-106, Jan. 2018. https://doi.org/10.1109/ LPT.2017.2777338

[8] D. Manandhar, H. Kim, C. Kim \& J. S. Lee, "25$\mathrm{GHz}$ Spaced Spectrum-Sliced WDM PON Using 50GHz AWGs," IEEE. Photonic. Tech. L., vol. 27, no. 13, pp. 1383-1386, Jul. 2015. https://doi.org/10.1109/ LPT.2015.2421737
Fabian Cuesta Quintero graduated as a systems engineer from UFPS (Cúcuta, Colombia). In 2013 he received the degree of Specialist in practical university teaching, at UFPS Ocaña and his Master in mobile telecommunications at the Universidad Distrital Francisco José de Caldas (Colombia). Since 2009, he is Assistant Professor and coordinator of the laboratory of networks and telecommunications of the Department of System Engineering and Informatics of the University Francisco de Paula Santander (Ocaña, Colombia). He is the author of a book. His research interests include everything concerning networks and telecommunications, both wired and wireless media. https://orcid.org/0000-0002-0230-9445

Gustavo Adolfo Puerto Leguizamon received his MSc. and PhD. in Telecommunications Engineering from the UniversitatPolitècnica de València (Valencia, Spain). In 2006, he founded the Laboratory of Microwave, Electromagnetism and Radiation (LIMER/ GRECO) research group at the Francisco José de Caldas District University (Bogotá, Colombia). In 2007 he became an associate professor at this University. He has published more than 40 papers in journals and international conferences, and he is a reviewer for the Chilean Journal of Engineering and the Journal of Antennas and Propagation (IJAP). His research interests include wideband and multi-band planar antenna design and optimization, microwave engineering, and applied electromagnetic and small satellite communication systems. https://orcid.org/0000-0002-1460-5831

Carlos Arturo Suárez Fajardo received his MSc. and PhD. in Telecommunications Engineering from the Universitat Politècnica de València (Valencia, Spain). In 2006, he founded the Laboratory of Microwave, Electromagnetism and Radiation (LIMER/ GRECO) research group at the Francisco José de Caldas District University (Bogotá, Colombia). In 2007 he became an associate professor at this University. He has published more than 40 papers in journals and international conferences, and he is a reviewer for the Chilean Journal of Engineering and the Journal of Antennas and Propagation (IJAP). His research interests include wideband and multi-band planar antenna design and optimization, microwave engineering, and applied electromagnetic and small satellite communication systems. https://orcid.org/0000-0002-1460-5831 